\title{
The effect of misapplied religious practices in some alternative religious groups
}

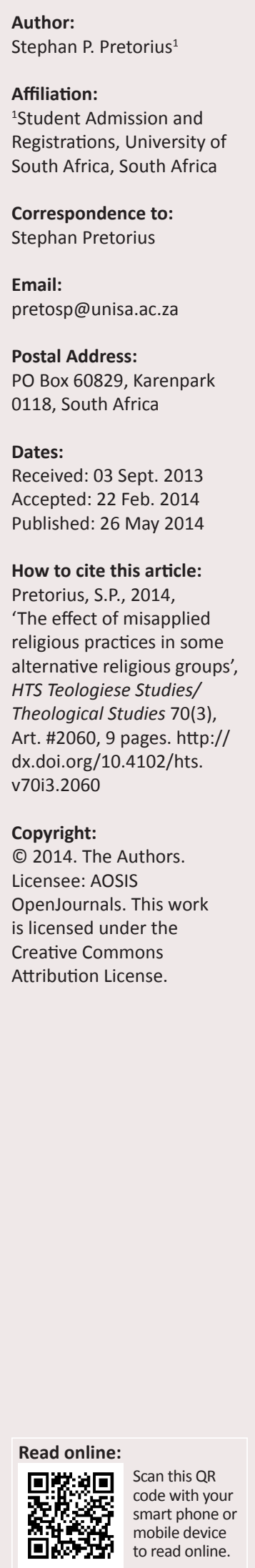

The positive impact that religion generally has on human beings has been suggested by different studies. However, it cannot be assumed that religion always contributes to the wellbeing of believers. Religious systems can be misused, resulting in people being spiritually and even physically hurt and harmed. This study investigates certain aspects of some alternative religious group in order to determine the impact it has on the well-being of the members of these groups. It was found that people are drawn to these groups because of the challenges they present, the display of true love amongst members and the 'message' of an authoritative charismatic leader that resonates with them and convinces them to become part. As time pass, members were challenged with questionable aspects that appear in the activities and teaching of these groups. Obtaining clarity on these concerns was strongly discouraged by the culture and other members of the group, resulting in members suppressing doubts and emotions. Adherence to the tenets of the group then occurred as a result of peer pressure and out of fear instead of true conviction. The study concludes that most of the respondents in the study reported that their experience in these groups did not contribute to their well-being, and emotionally, they struggled to adapt to society and other religious groups after leaving the group.

\section{Introduction}

Religion forms a central part of people's lives and dictates their view and interpretation of the world, their coping with occurrences in daily life and even their expectations of eternity. Religion is formative and determine how people arrange their lives, act and sacrifice in order to obtain salvation or enlightenment. It may mean that believers will sacrifice their earthly well-being and even endure earthly suffering in order to obtain eternal salvation.

It seems appropriate that, in order to discuss the misapplication of religious practice, that religion needs to be defined. The definition of religion is vague and contested. An attempt to reach 'a substantive widely applicable and widely acceptable description' is unlikely, based on the different interests in and approaches to the study of religion (Sweet 2012:161). A workable definition of religion in this context is that religion is a belief in the existence of a supernatural ruling power referred to as the creator that controls the universe and has also endowed man with a spiritual nature which continues to exist after the death of the body. It also refers to the body of persons adhering to a particular set of beliefs and practices (Dictionary.com n.d.). For the sake of this study, however, the definition of religion is not as important as the experiential aspect of religion resulting from the practices and the authority of the leader. Furthermore, what is important is how that experience contributes to the spiritual behaviour of members and whether that behaviour serves the well-being of members. A further important aspect is to distinguish between institutionalised religion that refers to religion that takes place within a formal organisation, such as the Presbyterian or Roman Catholic Church, and non-institutionalised religion that refers to religion found outside of formal organisations (Davidsen 2012:557). In this study, alternative religious groups are classified as non-institutionalised religious groups. They have diverted from Christianity leading to de-Christianisation, and they have diverting from the church, de-ecclesialised, but they remain Christian in their own view, finding their spirituality mainly in the authoritative individual experience and revelation of a religious leader (Davidsen 2012:554). The particular relationship of members with this religious authority and his or her teaching and the impact it has on their social behaviour and internalisation of the revelation and teaching of the leader are of interest in this study.

In general, however, society seems to believe that people's well-being within their religious context is ensured. A few radical religions are the exception. The religious context is after all the environment to which people retreat in order to gain spiritual strength for the challenges that life holds. Although religion is generally believed to represent unassailability, it can unfortunately also be misused to exploit people. 
The aim of this article is to evaluate the general assumption that religion contributes positively to the well-being of believers, specifically with reference to alternative religious groups. The impact of religion on the well-being of believers will be reviewed below. A study was done with 16 former members of four different alternative religious groups and six parents of members involved in these groups. Two of these groups were situated in urban areas in Gauteng and KwaZulu-Natal, respectively, one in a rural area in Limpopo Province and the other one in a rural area in Mpumalanga. The focus of this study is to evaluate the impact that the dynamics, teaching and authority of the leaders of these groups had on the wellbeing of the members and their families. The sensitivity of the study, the vulnerability of the participants and the fear of potential harm if they disclosed any information about these groups complicated attempts to obtain more participants. In the light of the aforementioned, the participants and affected groups will remain anonymous. They participants will be referred to in this study as respondents ${ }^{1}$.

\section{Clarification of terms}

The focus of this study is on religion in general but more specifically on a specific classification within religion namely 'alternative religious groups'. An 'alternative religious group' is also described by scholars as a 'new religious movement', 'new religion', 'sect', 'cult', 'high-demand religion', 'abusive religious group' or 'manipulative religious group'. In this context, an 'alternative religious group' can be defined as a religious group that functions separately from any mainstream religion, either in geographic isolation (i.e. commune) or within society. Although such a group may function within society, its members normally adhere to the internal tenets of the group that ensures varying measures of secluded life in terms of participation in societal affairs. Members of alternative religious groups commit wholeheartedly to the commands and demands of the group at whatever cost to their families and themselves. The authoritative leader of the group is mostly believed to be revered and feared by the members of the group, mostly in light of the conviction that he or she has a special calling and gift to determine not only their earthly but also eternal destination. The 'only truth' believed to be key to their fate is also in the possession of the leader and within the confines of the group. Family and friends further observe radical changes in the behaviour and attitude of their loved ones as a result of their involvement in the group (Pretorius 2010).

Three concepts are important and interlinked in this study, namely spirituality, religiousness and religion. Spirituality has been defined in many ways and, depending on the definition, can be narrower, broader or largely independent in meaning from religiousness (Wink 2003:916). Spirituality refers to 'the transcendental, addressing the ultimate questions about life's meaning with the assumption that there is more to life than what we can see or fully understand' (Fetzer Institute 1999:2), 'a boundary-less dimension of human experience' (Culliford 2011:1), a deeply personal, subjective experience and the awareness that there is meaning and purpose in life.

1.The respondents that took part in the study completed a consent form that indicated that he or she participated voluntary and gave permission that the results can be used for publication in a scientific journal.
Inclusively, spirituality refers to that which gives meaning to people's lives and enables them to transcend themselves and to find expression in prayer, meditation, interactions with others or nature, spiritual experiences and a relationship with God or a higher power (Burkhardt 1989). Spirituality refers to a person's connectedness with the transcendental reality, higher being or God made attainable through religious doctrines. Spirituality refers to the connectedness on the transcendental level that can 'individually manifest on the cognitive, emotional, motivational and behaviour levels and can also have social and cultural effects' (Kohls et al. 2011:1839). In this article, the connectedness of the members through the authoritative leader and particular group to the transcendental level as well as its impact on their behaviour will be pointed out.

In contrast, religiousness can be distinguished from spirituality, according to Wuthnow (1998), through the concepts of a religious dweller and a spiritual seeker. Religiousness refers to the religious dweller that accepts the religious traditions and forms of religious authority and finds a dwelling place in the space that has been created by these religious institutions and interacts through the rituals and practices of religion. Spirituality is likened to a spiritual seeker that supersedes institutional religious traditions and explores, seeks and creates a spiritual connectedness and experience with God. Spirituality places greater emphasis on spiritual growth and development.

Religion in this context is characterised by the system of worship and doctrine as expressed in specific behaviour and social, doctrinal and denominational or group-related practices and rituals. Religion aims to foster, guide and provide a framework to nourish that religious life. In this article, religious life refers to the impact that the specific doctrine of 'truth' and the leader have on the life style and behaviour of members not only inside these groups but also with family, friends and the community outside the group.

In this study, three aspects will be taken into account, namely (1) how the religious belief embodied in the message of 'truth' is accepted by members and how it guides their religiousness, (2) the authority of the religious leader and accompanying levels of submission and (3) the interdependence of and bond between members of these groups and how these aspects impact on their spirituality and well-being.

\section{Assumptions and findings about religion}

Most religions are believed to provide a system of meaning that enables people to cope with the questions and challenges of life (Ferraro \& Kelly-More 2002:220). Religiously active people experience higher levels of marital and sexual satisfaction and happiness and tend to be healthier than irreligious people (Glynn 1999). They are also less likely than irreligious people to abuse drugs and alcohol (Johnson \& Jones 2000). 


\section{Religion's impact on the well-being of believers}

Different studies have been conducted to determine the impact of religion on people's lives in general. A study done by Gallup and Lindsay (1999) in America suggests that the importance of religiosity or spirituality intensifies when people grow older compared to younger or middle-aged adults. Females tend to be more religious than males (Francis 1997; Thompson \& Remmes 2002). Believers have a positive outlook on life that can significantly help recovery from cancer (Ai 2006), and religious people display less distress when challenged by the setbacks or anxiety of life (Inzlicht \& Tullett 2010). Religious concepts also assisted believers' ability to endure negative experiences in a number of behavioural domains, and it is believed that 'invoking religious beliefs may provide important psychological "nutrients" necessary for a variety of socially beneficial behaviors' (Rounding et al. 2012:640).

According to the studies below, religiosity or spirituality has a significant impact on the well-being of people. Hill and Pargament (2003) and Klemmack et al. (2007) classified people in highly, moderately, somewhat and minimally religious groups in order to determine the relationship of each group to the wellbeing of the believers. The highly religious group displayed a positive relationship between religiosity or spirituality and mental health. The moderately religious group displayed a less positive relationship with mental health. Minimally religious people had fewer depressive symptoms compared to the moderately and somewhat religious group. One reason for this is that highly and moderate religious people that have higher levels of stress turned to religion or spirituality as coping mechanisms in time of stress or health complications (Koenig, McCullough \& Larson 2001; Pargament 1997). Greenfield, Vaillant and Marks (2009) determined that spiritual perception took primacy over religious activity when it comes to the psychological well-being of believers. This does not suggest that the benefit of formal religious activity should be minimised, seeing that institutionalised religious activity as well as individual spiritual activity are independently associated with dimensions of psychological well-being. More formal religious activity was beneficially linked to aspects such as purpose in life and personal growth. The lower levels of autonomy and self-determination of believers associated with formal religious activity can be contributed to the comfort believers find in the sense of the divine influence in their life. (Greenfield et al. 2009:204).

Although sufficient evidence exists to suggest that religion and spirituality have a positive effect on the physical health and mental health of the believer (Koenig et al. 2001; Pargament 1997), it became evident that problems with health and well-being spur on religious seeking (Ferraro \& Kelley-Moore 2002). When faced with physical and mental health issues, including depression, people generally turn to religion or spirituality in an attempt to find meaning and comfort (Ferraro \& Kelley 2002:231).

The above research suggested the positive influence of religion on the well-being of people but also indicated that ill health spurs on religious seeking in a quest to find consolation. It furthermore suggested that the frequency of religious participation influences the levels of happiness and well-being. The bond that is formed amongst religious members also contributes to their well-being. Although the above studies generally report the positive impact of religion on humans, they do not deal with the possibility that religion may also impact negatively on the well-being of believers.

\section{Susceptibility associated with religion}

An aspect often overlooked in spirituality is the susceptibility of religious people as a result of the dynamics of religion (Engel 2011; Pretorius 2012). The prescriptive and authoritative nature of a belief system can supersede rationality and weaken the senses, as is evident in the justification of actions such as burning somebody at the stake, the decapitation of unbelievers, participation in a 'holy war' or the catastrophic cruelty as was witnessed on 11 September 2001 (Cleary n.d.:1-4). Mental illusions concerning what is believed to be the 'will of God' can separate the mind from reality. Religious extremism is motivated by the belief that any action performed in the name of God denies primary and foundational reservations and does not value human life, as is evident in the case of a suicide bomber. Although this action believed to provide a greater good is justifiable in the context of the particular belief, it still displays the potential vulnerability of the believer to self-sacrifice. Further, it also cautions about the potential that this vulnerability can be exploited for own selfish goals. Universal religion is characterised by the belief that unseen forces are at work, impacting on the physical existence but also on the eternal life of people (Engel 2011:2). Religion, because of its transcendental nature, defies proof and cannot be evaluated against any earthly criteria, and it surpasses earthly institutions and goods and may not be compromised. Disobeying the commands of a religion is believed to lead to illness and misfortune and even to being lost for eternity (Engel 2011:6, 10).

The impact of the dynamics of religion is visible in the inordinate amounts of time members of alternative religions spend in the activities of their group, also in the isolation and withdrawal from society (Pretorius 2012:200). The vulnerability of believers in a religious context needs to be considered when assessing their well-being. The assumption cannot be made that religious activity always contributes to the well-being of believers. It is essential to determine how the dynamics of religion are applied by religious leaders and what mental and emotional state it creates with the believer. It is also important to be aware of the fact that a religious belief system that appears to be sound and authentic could be cunningly misused to obtain the self-serving goals of the leader.

\section{Aspects of the religiousness and spirituality of members of alternative religions evaluated}

Through interviews and questionnaires, the experiences of former members and the parents of members in the same alternative religious groups were evaluated in terms of 
the following: What is the main doctrine of the group they belonged to, and how important is the role it played in their spirituality and behaviour? Secondly, how do they view the religious leadership of the group to which they belonged? Thirdly, what are the relationships amongst members of the group and with their families and friends? The aim of this evaluation is to determine the impact of the dynamics of these groups (with special reference to the above aspects) on the behaviour and ultimately the well-being of members.

The questionnaire, firstly, aimed at obtaining information on the doctrine of 'truth' presented in these groups by asking how the members viewed the doctrine of the group. They were asked whether they believed that it was the only 'truth' and if adherence to that 'truth' was the only way to obtain salvation. The questionnaire probed what would happen if they disobeyed the truth and whether they were allowed to question this truth. Secondly, respondents were asked to express their view of the leader, how they viewed his or her authority, why they believed that the leader was authoritative and what impact the authority of the leader had on their personal life and behaviour. Lastly, the respondents were asked about the relationships in the group. They were also questioned about the effect of the aforementioned aspects on their relationships with one another and with their families and friends outside of the groups. The questionnaire consisted of questions with multiple answers but also provided for their own answers or additional information at each question. The respondents could include either additional information or their own information if the answers provided were not applicable in their particular case. The possible answers were provided in the form of multiple options, and they were answers generally provided to similar questions in previous research amongst a number of other alternative groups. The questionnaire could also be used to determine whether the notion that there are almost generic answers to certain questions pertaining to these groups is indeed true. It turned out that the largest number of members that responded did indicate similarities in their response. The evaluation and summary of the results follow below.

\section{The truth}

As was indicated before, the doctrine, in this context referring to the particular interpretation of the Bible and accompanying revelation of the leader, of a religious group is paramount in the behaviour of members. The doctrine, believed to be a directive from God, determines not only the respondents' worldview but also what is required to obtain salvation. Absolute obedience to the tenets of the groups is a requirement for a sound relationship with God.

Each of the groups that were evaluated had a specific doctrine apart from the text of the Bible. Respondents of one of the groups indicated that the prominent doctrine of their group is that their leader represents the second coming of Christ. Respondents from another group indicated that their doctrine is known as the 'gospel of the cross', which implies that members have to identify with Christ and take up their own cross in order for their 'twisted hearts' to be changed. Another group's central teaching is that their members need to be separated from the world as a community of believers with their own identity and that spiritual growth is only obtained through membership of the group. Most of the respondents indicated that they believed the doctrine wholeheartedly and did not question it. Only two of the respondents indicated that they had questioned the doctrine after they had been in the group for a while. Members who questioned the doctrine of their groups met with hostility from the leaders. They were accused of being 'unspiritual' and allowing doubt, placed by the evil one, to creep into their minds that would eventually pull them away from the truth. One respondent indicated that, when members were allowed to ask questions, the leader answered the questions without really dealing with the question. The answer was merely a means to pacify the enquirer.

Most respondents indicated that questioning the 'truth' or teachings of the group in order to obtain clarity was discouraged and viewed as mistrust in the leader's authority and rebellion against God. Questioning the teaching displays unbelief and critical thinking that nullifies the important principle of religion - 'blind' faith. Acceptance of the truth in the group is viewed as spiritual maturity and questioning the truth as immaturity. Only one respondent indicated that she felt at liberty to ask questions.

Most of the respondents indicated that, although they had experienced doubt and had questions, they had suppressed their questions because it was suggested that questions or doubt are the result of their fleshly minds that have not yet been aligned with the truth and the higher good of the group. Respondents were not at liberty to share their doubts amongst each other because of the belief that such action would mean disloyalty and betrayal of the leader but also because some members acted as spies for the leader. Members expressing doubts were publicly reprimanded and labelled as rebellious. Any doubt must be directed to the leaders since the leaders are spiritually advanced and able to provide clarity. Whilst in the group, members disguised doubt so well that the illusion was created that nobody had any doubts, it later became evident that other members also had doubts but 'questioned the doubts in silence' out of fear for the repercussions.

Disobedience to the truth and tenets of the group would, according to respondents, mean that they have turned their backs on God and would be struck with illness as a result. One respondent reported that she was told that, if she left the group, she would never be able to return because she had fallen too far to ever be accepted back again - she was 'beyond repair'.

When family members confronted their loved ones about the practices and teaching of the group, they mostly refused to listen to other viewpoints, they avoided any discussion concerning the group, they became upset when the topic was discussed and withdrew, and they said that their family's reaction stemmed from ignorance of the truth. Even when 
they were confronted with deficiencies in the leader such as fraud, lies or rape, they either denied it or justified it by saying that they knew the leader and that he or she was a wonderful person and would never do that, or that it was a lie made up to discredit the leader.

Family members of the affected former members reported that they questioned the leaders of these groups about their doctrine and practices and were met with different responses from the leader. These ranged from initially being polite in answering the questions but becoming rude later to accusing the family member of being a servant of the devil that attempted to cause their family member to stumble.

Respondents generally reported that the leader twisted the message of the group to obtain greater commitment from the members. In one of the groups, the message had to be changed in order to curb a loss of members resulting from the sentencing of their leader to prison. Whilst on trial, the same leader made his members pray and fast so he would have a positive outcome in his trial. When he was found guilty, he went back on his word and said that the outcome was God's will and that the members were keeping him from God's will by praying for a positive outcome. Other respondents reported that the message of the group was changed when faced with opposition from outsiders, but it was only for a while until the opposition softened. Other respondents reported how a specific message was shared with a specific 'spin' to deliberately influence potential members. In another group, the leader found out more about some members' problems, doubts and concerns and reported it to the main leader who would adapt his preaching to deal with the issues. The affected members would view this as a sign of the advanced level and spiritual insight of the leader into their personal lives.

Respondents generally indicated that they would obey the tenets of the group whatever the cost, even if it had a negative impact on their own and their families' well-being. They further reported that they would rather obey the tenets of the group and disobey a law of the country or lie to authorities in light of the fact that God's will supersedes secular laws. The principle that justified their conduct was that 'the end justifies the means'. Some reported that they had to lie to customs officials about the reasons for visiting a foreign country, and they were advised to produce incorrect information on their visa applications. Moving the same money from one account to another has also superficially created the illusion of sufficient money in a bank account, a requirement for visa applications. Others had to smuggle vegetables into a foreign country for the leader's wife. One responded that held the position of legal secretary to a lawyer who was part of the group and had to type legal letters containing lies and twisted truths to defend the group or gain benefits for the leader from local authorities.

In summary, the feedback suggests that, in all of the groups, a specific doctrine, believed to be their unique own 'truth', served as an important unifier between members and was regarded as fundamental for the functioning and behaviour of the members of these groups. It became evident that the 'truth' or message in these groups has changed over time to fit the modus operandi of the group, consequently resulting in affecting the members' position towards the 'truth'. Initially, members seemed to be convinced by the truth but later acted out of fear of displeasing God, upsetting the leader or disappointing the other members. The fact that members were encouraged to share their doubts only with the leaders deterred the spread of doubt amongst members that would affect the loyalty of other members. In a subtle way, members' right to freely associate and express themselves are sacrificed for the sake of group coherence. No 'written rules' are prescribed for the above actions of members in these groups, but so-called 'unspoken rules' have been established over time through peer pressure, modelling of members and the internalisation of what members believe to be the correct behaviour. The unhealthy and constant cloud of fear for the evil, for displeasing the leader and for disobeying God directed members' thoughts and behaviour. The leader's uninviting reaction to doubt and the critical behaviour of members further confirms the discouragement of critique or rational contribution in any form. Members have been established in a polarised world - the safe environment of the group that ensures salvation against the evil outside world. The only sensible choice to stay in God's will is to withstand the evil onslaught in whatever form, even if it comes to them through their loved ones.

\section{Spiritual leader}

This part of the survey focuses on the leaders of these groups, how their positions were viewed, the level of authority they enjoyed and the impact it had on their members. The evaluation of the authority and position of the religious leader in the identified groups leads to the following results.

Despite the different positions respondents held in the hierarchy of the groups, most believed that God called their leader because he possessed special gifts. Only one respondent indicated that she believed that the leader had no special gift. These special gifts include humility, special insight and knowledge of the Bible and a special revelation from God. Some respondents indicated that their leader had the ability to hear directly from God and had a special anointing. Some also reported that they believed that the leader had admirable wisdom, could see in the spiritual world, knew what lay ahead for the members and had 'special insight into what made people tick'.

The belief that the leader had a special gift and calling had a definite influence on the members' decision to join the group. Initially, the teaching of the leader that resonated in members' hearts as true, and their belief that he was anointed convinced them to join. The fact that groups offered challenges that would make a difference in the world, challenges that were absent in their original church, and the sense of belonging and initial unconditional love in the group were important reasons why people have joined. 
The leader in one group was seen as the living Christ, the reincarnated Messiah, on earth for this period of time, and therefore, he had godly sanctioning. Later, after this leader was imprisoned for fraud, this claim changed, and he now claimed that he was the anointed one preparing the way for Christ's second coming. Respondents from another group believed that their leader was a true apostle.

When the respondents were asked about their emotions towards the leader whilst in the group, they mostly reported that they experienced admiration, respect, fear, trust and love for their leaders. One respondent said that he did not really experience admiration and respect towards the leader but tolerated him because it was expected of him. Respondents mostly declared total submission to the leader to the extent that they would perform actions even if it impacted negatively on their own and their family's well-being. Most reported that they believed that disobedience to the leader would cost them their salvation.

Respondents were asked whether they believed that the influence of the leader and his position had an impact on their salvation and personal relationship with God. Some respondents reported that they believed that their relationship with Jesus was good whilst they were in the group. One respondent remarked: 'It was the closest I have ever felt to Him.' Other respondents reported that, what they had thought to be a good relationship with God, later turned out to be nothing more than an emotional hype. Other respondents reported that the leader became the mediator between them and God and that pleasing the leader equalled pleasing God. Their personal relationship with God was eventually mostly replaced by being obedient to the commands of the leader and the group. Also, the culture of the group interfered with their personal relationship with God over time. One respondent believed that his prayers remained unanswered because he did not involve the leader in these requests.

Respondents generally did not doubt the authenticity of the leader initially, and later when they developed doubts, they justified the questionable actions of the leader by saying that, despite the fact that God uses earthly broken people as his messengers, the message is still true. That they were not allowed to speak or think negatively about the leader was according to them in line with the Bible that teaches, 'do not touch the anointed of God' (Ps 105:15). God would deal with the wrong actions of leaders, and they had to keep out of it. Another respondent that witnessed their leader's imprisonment for rape and money embezzlement reported that she dealt with it by denying it and by not thinking about it. Other respondents believed that reports about their leader's behaviour were all lies in order to discredit the leader. Some respondents reported that such reports concerned them, and they started to question the leader's authority and discussed it with others. Other members believed that the explanations the leader gave for his actions justified those actions.
The family members of the respondents concurred with what the members expressed on the position and authority of the leader. They also reported that the members' absolute belief in the authority of the leader was manifested in the refusal to listen to other viewpoints and in their belief that the teaching of the leader was the ultimate truth. Respondents were also asked about the emotions they experienced towards the leader after leaving the group. Respondents generally reported that they experienced anger because they were deceived this way, disappointment that they have been deceived, hate towards a deceiving leader and certain members in the group, a lot of confusion, pity for the people that are still in the group, grief for everything they went through, loss or longing because respondents indicated that they have lost time out of their life and fear that the leader and group would keep evangelising and bring others to the group. Other members added the emotions of betrayal of their trust, that they were taken advantage of, indignation, resentment and that their rights such as freedom of association and freedom of speech were violated.

It is evident that members have developed strong emotional feelings whilst in the group. These did not only have a bearing on their well-being then but continued to influence them even after they had left the group. Despite the different views about the influence of the leader on their behaviour, it became evident that the belief that the leaders were specially chosen persons with 'godly sanctioning' interfered with the members' personal relationship with God to a lesser or greater extent. The initial 'good' emotions towards the leader turned to negative emotions when they realised that they were deceived. It had a recurring effect on their own adapting to society, another religion and family and friends.

\section{Camaraderie - sense of unity}

The strength and impact of the bond that is formed amongst members of these groups must not be underestimated. The two aspects mentioned above, namely the authority of the leader and the belief that the group has the only truth, ensured a feeling of special election. Those that formed part of the specially elected group were bonded together in a special way as true conquerors for a higher cause. Rejection by the world even strengthens the belief of special election.

The bond amongst members in these groups and its impact on their families were evaluated. Respondents in general reported that they felt special in the group and experienced unconditional love as never experienced in any group before, even in mainstream churches. They felt superior to other religious groups. Only one respondent reported feeling lonely, caused by his alleged 'blockages' and suspicious attitude about the group. The leader instructed him to step out in faith and trust in him as the leader of the group. Respondents believed that the closeness they experienced as a result of being God's specially chosen united them. The hardships in fulfilling God's purpose made them bond in a special way. They shared intimate details that made them feel closer and willing to sacrifice their lives for each another. 
Other members said that they realised that there was a higher loyalty to the group than to any friendship.

Other members' behaviour towards the leader and the group had an impact on their own behaviour. Respondents reported that other members' behaviour placed pressure on them and became a yardstick for their spiritual development. It also assisted with conforming to the group culture and not standing out as rebellious. Doubts in their own life were dealt with by looking at the other members' actions. If other members acted normal and looked happy, it was an indication that they were lacking spiritually and needed to change. Respondents reported that old members definitely also fulfilled an important role in luring new members to the group by presenting the group and its aims as respectable and admirable and better than other groups to potential members. Old members in the group were groomed to shower new members with attention and love and to establish a sense of belonging. Certain respondents reported that they were trained in recruiting new members based on their interests and personality types. One leader encouraged members to proselyte beautiful people because they would attract others. It became evident that peer pressure from other members and group identity were masterfully used to subtly force members to change or adapt their behaviour.

The group identity and camaraderie seemed to have impacted the member's relationship with family and friends. Although a few respondents did report that the bond with members in the group never took the place of their biological family, family members of members in these groups as well as most of the other respondents reported that they did indeed experience that the so-called spiritual family took the place of the biological family. Most respondents indicated that the establishment of the spiritual family as the superior family led to spontaneous alienation of family and friends. Some members were even subtly discouraged to maintain contact with family outside of the group.

With the establishment of the spiritual family came the pressure through the leader's continual encouragement for wholehearted commitment in order to obtain salvation and the subtle sense of guilt if they did not attend all the weekly meetings. Referral to other members' commitment resulted in greater commitment of respondents. Respondents' tasks and enforced and semi-enforced group activities, like fasting and praying together, systematically increased.

The strong unity amongst members seemed to motivate the largest number of respondents to revert to drastic actions for the group. In one group, members were renamed and received Bible names that would be representative of their position and role in the group.

It became evident through the report of respondents that the culture of these groups complicated exit from the groups even when members realised that the group had deficiencies and that its modus operandi was doubtful. Respondents reported in general that they were alienated from their support system such as family and friends and were physically and emotionally too tired to put up a fight and face the world. The strong emotional attachment with their fellow group members caused them to reconsider leaving the group. Some had all their family members with them in the group and as they were in disagreement about leaving and faced with losing their partner and/or children if they left, they reconsidered leaving the group. Others had as a result divorced their partners and parted with their children because they had left the group.

Reportedly the cultures of these groups established a false sense of spirituality but also material security, resulting in members' greater willingness to give their possessions, policies and vehicles to the group. This influence seemed to originate from the frequency of religious participation and the strong bond amongst members. Whenever respondents attempted to rationalise disagreement, they were persuaded, either by positives in the group or by another teaching or by little concessions that were made. Progressively, the culture of these groups made members reliant on the group, rendering members immobile and ineffective in self-support. Many respondents able to make rational decisions seemed to have become mostly followers of instructions.

\section{Discussion of results}

The aspects identified through the survey as well as interviews indicated that the dynamics of these groups have an impact on the well-being of individuals as indicated below.

The truth:

- The established belief that the group has the only truth closes down the possibilities for members to consider other viewpoints freely. All other viewpoints are considered as attempts to alienate members from the truth, resulting in their fierce mechanical rejection thereof in order to be conquerors of the truth.

- The authority of the truth is based on a special revelation from God confirmed by the special calling of the leader and, sometimes, special gifts.

- The 'truth' in these groups is manipulated to obtain submission and obedience to tenets and is misleading to the unaware members.

The authority of the leader:

- The 'godly' sanctioning afforded to the leader, whether directly or indirectly, establishes an unhealthy and risky trust relationship.

- No indication could be found that any of the leaders took corrective measures when they became aware of the unhealthy position of authority they held over their members.

- The inappropriate awarded authority of these leaders directly or indirectly established the belief that disobedience to the leader's commands equals disobedience to God and would result in some form of punishment and rejection. 
- The self-awarded authority of these leaders in most cases led members to believe that their commands transcend earthly institutions and need to be obeyed at whatever cost, even if it means alienation from family, breaking the law of the country or amount to drastic measures such as lying and even sacrificing your own life.

- The strong belief that the leaders possess godly sanctioning deterred members to leave the group out of fear that it would mean that they had turned their back on God and that they would be punished and be lost.

\section{Camaraderie:}

- Although the bond between members seems idyllic, it has a negative impact on the well-being of followers in that it places members under peer pressure to act without being afforded the opportunity to evaluate their own position in performing such actions.

- The strong bond of unity and group conformity and identity hinders and suppresses the personal individual rational facility and development.

- When taken up in the group, personal goals and ambition plays second fiddle to the higher good as envisioned in the aims of the group.

- The camaraderie found in the new 'spiritual family' led progressively to the deterioration of sound family bonds.

- Camaraderie ensures an inward-bound focus that leads to a lost of appetite in contributing to societal affairs outside the group.

Members that end up in these alternative religious groups seem to be genuine seekers of the truth, seekers for challenges and willing to make selfless sacrifices to make this world a better place and bring hope and salvation to people. At the realisation that they had been misled by the appearance and presentation of the group, they were discouraged and disillusioned. They realised that they had been let down by those whom they trusted most and to whom they had given their all. What turned out to be the utopia, the absolute place to exercise and live out their spirituality, had turned out to be the place where they had painfully come to realise the deep level of deceit through the subtle dynamics of the group. Their involvement in the group left them with more questions than answers about the true nature of religion. The emotions of disappointment, hate, confusion, grief, misuse, betrayal and being taken advantage of took the place of the inner peace they initially experienced. Back in the real world, faced with all the confusion and shame to admit that they had suffered and sacrificed much in vain, they struggled to work through the turmoil of emotions in the hope to find sense.

\section{Conclusion}

Although the results obtained through the study are not comprehensive, they clearly indicate certain tendencies in these groups worthwhile exploring. Furthermore, reluctance was encountered when efforts were made to include more former members. This reluctance was based on confusion, unsettled emotions and the belief that something terrible would happen to them if they speak out. Although respondents that participated differ in personality and character and deal differently with circumstances, it became evident that their involvement in the different groups had a negative impact on their well-being in terms of their own spirituality and their relationships with friends and family and their involvement and interaction with the broader society. The group, initially believed to be an authentic group of believers in a real relationship with God obeying his will, turned out to be superficial and a group that had lost track with the realities of this world. It is clear that the members that participated in the study expressed a strong religiousness based on the belief systems of each group. The spirituality aspect referring to a person's relation to broader life with all its aspects based on his or her personal interconnectedness with God seemed to be mostly reduced to an inward-bound living as was prescribed to them by the leader. Their spiritual experiences have been strongly influenced by their own internalisation of the recited doctrine and teaching of the group. Although religious doctrines have a specific influence on spirituality, in this case the religious doctrine did not provide a framework that allowed for prayerful reasoning and questioning in an attempt to obtain spiritual insight and growth. Religion should never be motivated by fear but is rather a place where people rid themselves from fear and guilt in obtaining assurance in the promises of God's Word.

\section{Acknowledgements Competing interests}

The author declares that he has no financial or personal relationship which may have inappropriately influenced him in writing this article.

\section{References}

Ai, A.L., 2006, 'Psychosocial mediation of religious coping styles: A study of shortterm adjustment following cardiac surgery', in American Psychological
Association, viewed 19 February 2013, from http://www.apa.org/news/press/ Association, viewed 19 February
releases/2006/08/religious.aspx

Burkhardt, M., 1989, 'Spirituality: An analysis of the concept', Holistic Nursing Practice May, 60-77.

Cleary, W., n.d., '17 dangers in religion: My suicide bomber training', in Cleary Works, viewed 20 December 2012, from http://www.clearyworks.com/Opinions/17 dangers_in_religion.html

Culliford, L., 2011, 'Spiritual wisdom for secular times', Psychology Today, viewed 21 February 2013, from http://www.psychologytoday.com/blog/spiritual-wisdomsecular-times/201103/what-is-spirituality

Davidsen, M.A., 2012, 'Future directions in the sociology of non-institutional religion', Implicit Religion 15(4), 553-570.

Dictionary.com, n.d., Religion, viewed 13 Mary 2011, from http://dictionary.reference. com/browse/religion

Engel, C., 2011, Law as precondition for religious freedom, preprints of the Max Planck Institute for Research on Collective Goods, Max Planck Institute, Bonn.

Ferraro, K. \& Kelley-Moore, J.A., 2002, 'Religious consolidation among men and women: Do health problems spur seeking?', Journal for the Scientific Study of Religion 39(2), 220-234. http://dx.doi.org/10.1111/0021-8294.00017

Fetzer Institute: National Institutes of Health Analysis Working Group, 1999, Multidimensional measurement of religiousness/spirituality for use in health research: A report of a national working group supported by the Fetzer institute in collaboration with the national institute of aging, Fetzer Institute, Kalamazoo, MI.

Francis, L.J., 1997, 'The psychology of gender differences in religion: A review of empirical research survey article', Religion 17, 81-96. http://dx.doi.org/10.1006/ reli.1996.0066

Gallup, G. \& Lindsay, D.M., 1999, Surveying the religious landscape: Trends in US beliefs, Morehouse Publishing, Harrisburg, PA. 
Glynn, P., 1999, God the evidence: The reconciliation of faith and reason in a post secular world, Prima Publishing, Roseville, CA.

Greenfield, E.A., Vaillant, G.E. \& Marks, N.F., 2009, 'Do formal religious participation and spiritual perceptions have independent linkages with diverse dimensions of psychological well-being?', Journal of Health Social Behavior 50(2), 196-212.

Hill, P.C. \& Pargament, K.I., 2003, 'Advances in the conceptualization and measurement of religion and spirituality: Implications for physical and mental health research' American Psychology 58, 64-74. http://dx.doi.org/10.1037/0003-066X.58.1.64

Inzlicht, M. \& Tullett, A.M., 2010, 'Reflecting on God: Religious primes can reduce neurophysiological response to errors', Psychological Science 21(8), 1184-1190. http://dx.doi.org/10.1177/0956797610375451

Johnson, E.L. \& Jones, S.L., 2000, Psychology and Christianity, Intervarsity Press, Madison, WI.

Klemmack, D.L., Roff, L.L., Parker, M.W., Koenig, H.G., Sawyer, P. \& Allmam, R.M., 2007, 'A cluster analysis typology of religiousness/spirituality among older adults', Research of Aging 29, 163-183. http://dx.doi.org/10.1177/0164027506296757

Koenig, H.G., McCullough, M.E. \& Larson, D.B., 2001, Handbook of religion and health, Oxford University Press, New York, NY. http://dx.doi.org/10.1093/acprof :oso/9780195118667.001.0001

Kohls, N., Sauer, S., Offenbächer, M. \& Giordano, J., 2011, ' Spirituality: An overlooked predator of placebo effects', The Royal Society $366,1838-1848$.
Pargament, K.I., 1997, The psychology of religion and coping, Guilford Press, New York, NY.

Pretorius, S.P., 2010, 'Family alienation is presented as a requirement for total commitment in some new religious groups', Journal for Christian Scholarship 46(3/4), 125-142.

Pretorius, S.P., 2012, 'The risk of overestimating and underestimating 'religious cults' in South Africa', Dutch Reformed Theological Journal 53(2/3), 194-207.

Rounding, K., Lee, A., Jacobson, J.A. \& Li-Jun, L., 2012, 'Religion replenishes self-control', Psychological Science 23(6), 635-642. http://dx.doi. org/10.1177/0956797611431987

Sweet, W., 2012, 'Models of religious freedom', Science et Esprit 64(2), 157-177.

Thompson, E.H. \& Remmes, K.R., 2002, 'Does masculinity thwart being religious?: An examination of older men's religiousness', Journal for the Scientific Study of Religion 41, 521-532. http://dx.doi.org/10.1111/1468-5906.00135

Wink, P., 2003, 'Religiousness, spirituality and psychological functioning in late adulthood: Findings from a longitudinal study', Psychology and Aging 18(4), 916924. http://dx.doi.org/10.1037/0882-7974.18.4.916

Wuthnow, R., 1998, After heaven: Spirituality in America since the 1950s, University of California Press, Berkeley, CA. http://dx.doi.org/10.1525/ california/9780520213968.001.0001 